\title{
Practices and Knowledges
}

\author{
Silvia Gherardi \\ University of Trento - Italy \\ silvia.gherardi@unitn.it
}

\begin{abstract}
The present article retraces the way in which, over the years, I have developed a posthumanistic approach to social practice on the basis of an Actor-Network sensibility and the way in which practice theory appeared in the literature on learning and knowing in organizations. From this background, I propose an epistemology of practice grounded on relationality, multiplicity, and transformation, and I approach practice as an empirical phenomenon from the perspective of knowing as an activity situated in working and organizing. From this point of view the central interest in practice theories becomes practice as a collective and knowledgeable doing.
\end{abstract}

Keywords: practice, knowledge, post-humanism, embodiment 
In a previous issue of Teoria e Prática em Administração (7/1, 2017) Theodore Schatzki wrote about the relationship of practices and people, offering a way of thinking about practices and people according to which these two phenomena are equally real while mutually dependent and co-responsible for social life. In the present article, I wish to explore a complementary view on practices offering to think about their relationship with knowledge. We have a common point of departure in assuming that practices have to do with activities, and we acknowledge that many practice scholars are concerned with what people do (e.g., Shove et al., 2012). Nevertheless, I argue that doing is not enough for defining a practice and that the concept of practice is more useful for empirical research when it is conceived as a 'knowledgeable doing'.

In the present essay I explore the relationship between knowledge and practice, knowledgeable practices, knowing in practice, and knowledge as a situated activity. I trace a tradition of sociological thought in practice theories that derives from the studies of scientific knowledge, that challenges the conventional understanding of 'social' as human-centered, and that operates a re-turn to practice within learning and knowing in organization. I anticipate that my understanding of practice is grounded in an actor-network approach, i.e. 'in a disparate family of material-semiotic tools, sensibilities, and methods of analysis that treat everything in the social and natural worlds as a continuously generated effect of the webs of relations within which they are located' (Law, 2009: 141). Such sensibility is important, within the panorama of contemporary practice theories, because it offers a theoretical conception of the social that does not separate activities, thought, feelings, matter, discourses and their collective cultural-historical forms. Without a theoretical conception of the social, one cannot analyze activities in situ and report on how knowledge always undergoes construction and transformation in use.

In this essay, I shall contextualize (in the first section) my approach to practice theories within the broader debate in the philosophy of social theories that discusses the changing status of knowledge and moves towards a definition of knowledge as an activity situated in practice. The precursors of the empirical study of knowing in situ were the socalled laboratory studies and, in section 2, I present their contributions to the study of knowledge practices. From those studies we have learnt how the boundaries between 'scientific' and mundane knowledge practices can be blurred, and similarly the boundaries between humans and nonhumans. Therefore, we can move (in section 3) to a formulation of a post-humanist practice theory that joins other post-epistemologies in the project of de- 
centering the human subject as the main source of action and moving from a formulation of practice theory as 'humans and their practices' to a vision of practice as the entanglement of humans, materialities, discourses, knowledges and any other relevant element in the situated activities. A posthumanist conception of practice enables a different conception of the 'social' in theories of social practice, since the social is not the 'other' of the 'natural'. The social is generated by material practices - as expressed in the term sociomateriality - and an empirical study of social practices focuses on how the social is done and holds together. Since my main interest is on practices as an empirical phenomenon and how to elaborate a methodological framework for studying practices in organizational settings, in the section 4, 5, 6, I illustrate its main focus: the sensorial and elusive knowledges embedded in knowing in practice; realities as enacted in practices; how all the practice elements achieve agency in their being connected and how practices are woven in a texture of practices.

\section{Philosophy of social sciences and the status of knowledge}

What is knowledge and which one is the 'correct' methodology for approaching it is an open question that I need to sketch briefly in order to position knowing as an activity situated in practice. It is necessary to start with the discredit of positivism in the 1960 s and the loss of credibility of its main assumptions: scientism (scientific method as the only valuable source of knowledge); naturalism (the unity of method across the social and the natural sciences); a regularity notion of causality (the regular association of $\mathrm{x}$ and $\mathrm{y}$ is both necessary and sufficient to talk about causality); an assumption that explanation entails prediction (and vice versa); a rejection of explanations in terms of mental or subjective states (like intentions or motives), a predilection for quantification and sophisticated statistical analysis, and finally a sharp distinction between facts and values (Baert, 2005). Nevertheless, we have to keep in mind that those positivistic assumptions were strongly associated with the establishment of sociology as a scientific discipline preoccupied with the nature of the scientific method and the distinctiveness of the sociological research. Later, in the 1980s, sociologists became more suspicious of holistic theories such as structuralism, functionalism, and system theory (Sciortino, 2009).

A renewed interest in meaning, language and critique arose in the late twentiethcentury social sciences (Baert \& Dominguez Rubio, 2009) when naturalist philosophy of social science was challenged by three intellectual strands: hermeneutics, Wittgensteinian 
philosophy, and critical theory. I mention only the first two in an attempt to highlight the move from knowledge conceived within positivism to knowledge conceived as an empirical phenomenon.

Gadamer's (1975) hermeneutics, in contrast with Dilthey, Rickert, and Weber who conceived of historical context, tradition, and prejudice as external factors that bias understanding and rationality, considered those factors as the very elements that make understanding possible. Each specific historical context discloses a horizon of understanding, and the hermeneutical task of the social sciences is to achieve a "fusion of horizons" whereby the interpreters and interpreted enter a hermeneutical dialogue. The liberation of meaning from logics brought into focus the relations between meaning, practices and language. Moreover, the interest in meaning-making lead to the rediscovery of the phenomenological tradition, and in particular of Alfred Schutz's work (1962, 1964) which focused on the "common-sense world." Different from scientific rationality, commonsense rationality operates within a taken-for-granted world where people suspend disbelief. Schutz's phenomenological sociology and Berger and Luckmann's (1966) constructionist research institutionalized the assumption that the categories, through which people interpret social reality, help as well to create the world (Weinberg 2008). Social constructionism has contributed to the empirical investigations of what counts as genuine knowledge and why. Therefore, knowledge becomes an observable and researchable phenomenon rather than a merely imagined normative ideal.

Also for Wittgenstein (1968), meaning is irreducible to any rule-following method but it derives from the use of language within what he called a language-game, and to give an account of the meaning of an utterance we need to describe how the utterance is used within a specific language-game. The agreement reached by using a language-game, is not simply a convergence in opinions but an agreement reached by sharing a specific form of life. Social constructionism also referred to Wittgenstein to argue against the possibility of establishing universal and objective knowledge claims.

Schutz's work, together with Wittgenstein's, influenced Garfinkel's (1967) ethnomethodological studies of the micro-mechanisms of social order. Both hermeneutics and ethnomethodology influenced Giddens' (1984, 1993) structuration theory, which explores the various ways in which people's sense-making practices contribute to the making of social order. 
Another important and powerful critique to foundational philosophy of social sciences comes from the so-called pragmatist turn that rediscovered the early pragmatism by Dewey and neo-pragmatism (Rorty 1980, 1982). The Pragmatist school is skeptical of scientific knowledge as representing the inner nature of the external world: knowledge should no longer be seen as mirroring or representing the world "as it really is". Pragmatists argue instead for the primacy of the agent's point of view and knowledge acquisition is seen as active, as one of the tools that people have to cope with the world, using as resources (and not as limitations) the conceptual framework, language, and cultural setting in which they are situated.

With this critique of foundationalism comes a rejection of any philosophical attempt to capture the scientific method. The boundaries between scientific knowledge and ordinary knowledge become blurred.

\section{Knowledge practices: the laboratory and everyday life}

In the 1970s, the social construction of scientific facts and scientific knowledge became studied as a field of social practices like any other. The ethnographic methodologies were used in laboratory studies (Callon 1986; Clarke \& Fujimura 1992; Collins 1985; Gieryn 1999; Knorr-Cetina 1981; Latour and Woolgar 1986; Lynch, 1993; Pickering, 1995; Rheinberger 1997; Traweek 1988) resulting in rich descriptions of the mundane practices related to science, scientists, technologies and innovations. Knowledge practices were looked at as paying attention to the unique relations between things that are brought together in laboratories' activities, following the ethnomethodological principle that science is what scientists do.

In The Manufacture of Knowledge (1981) Karin Knorr Cetina, who was studying a food lab in Berkeley, observed how scientific facts are constructed within the context of social life and are fabricated by social consensus and experimenters' expectation-based tinkering. Laboratories' practices were described as an opportunity-directed to networks of scientists connected through resource relationships (either materials and tools) and the raw material of ideas. In her later book, Epistemic Cultures: How the Sciences Make Knowledge (1999), where high-energy physics and molecular biology labs were studied as knowledge cultures, Knorr Cetina examined the way the machineries of knowledge construction are themselves constructed. Objects of knowledge are always in the process 
of being materially defined, they continually acquire new properties and change the ones they have. In this sense, she presents an ontology of the object of knowledge based on an open-ended becoming rather than a fixed being.

From Knorr Cetina (2001) I shall borrow the term 'epistemic practice' to refer to the kind of practice that has knowledge as the object of inquiry, while by the term 'knowing-in-practice', I refer to a knowledgeable doing in accomplishing a practice. Knowing as a situated activity can be studied either in the context of a situated activity (a practicing) or as the object of practitioners' reflection on a practice, after practicing. Similarly, we can observe talking in practice and talking on practice.

With the progressive institutionalization of Science and Technology Studies (STS) the elusive boundaries between science and non-science, scientific and non-scientific knowledge were taken-for-granted (Roosth \& Silbey, 2009) and we can say that the 'manufacture of knowledge' is work done within laboratories' practices in a way not dissimilar from the way it is done in any other working practice. Moreover, in both cases the knowledgeable doing of the expert practitioners are open to the knowledgeable practices of non-experts. We saw it in the case of museums (Star \& Griesemer, 1989) where lay persons participate to the production of natural sciences and gay activists contributed to the understanding of AIDS treatments (Epstein, 1996). The so-called 'daughters of DES' expanded the knowledge about the long-term consequences of estrogen and became political activists (Bell, 2009) and ordinary patients contribute to medical knowledge and tools' developments.

Laboratories studies and science and technology studies made visible how the concept of practice connects 'knowing' with 'doing'. It conveys the image of materiality, of fabrication, of handiwork, of the craftsman's skill in the medieval bottega d'arte. From the Latin verb facere, Knorr-Cetina (1981) uses the term 'facticity' and Bruno Latour (1987) the 'fabrication' of scientific facts and technical artefacts. Knowledge consequently is fabricated by situated practices of knowledge production and reproduction, using the technologies of representation and mobilization employed by scientists. The term 'knowing-in-practice' (Gherardi, 2001; Orlikowski, 2002) sanctions the passage from the noun to the verb, suggesting how knowing is an enactment and an accomplishment, rather than a thing or a static property. What is known constitutes itself in knowledgeable doing, in purposeful activities, and it is 'situated in practice' (Suchman, 2007). Knowing-in-practice only becomes meaningful in relation to a distinct social practice. Due to its embeddedness in 
social practice, knowing is necessarily in permanent flux, and it entails a procedural understanding of the ability to act of all the practice elements once connected and reconnected. In other words, knowledge emerges from the context of its production and is anchored by (and in) material supports in that context.

To convey a preliminary idea of the theoretical and methodological framework in which working practices may be analyzed as knowing-in-practice, I summon its characteristics in the following way:

- A pragmatic stance. Practical knowledge is directed to doing, to making decisions in situations, to solving problems, to maintaining and reproducing a texture of practices;

- A specific temporality. Practical knowledge emerges from the situation and from situated activities;

- An anchoring in materiality. Practical knowledge uses fragments of knowledge embedded in knowledgeable bodies, objects and technology, and in the material world that interacts with humans and interrogates them;

- $\quad$ An anchoring in discursive practices. Practical knowledge uses the discursive mobilization of cues for action and their positions within a narrative scheme that gives sense to what occurs in communication;

- $\quad$ A historical-cultural anchoring. Practical knowledge is also anchored by what has happened in the past and has been learned from experience and in experience. If we consider the setting in which practices are accomplished, we have to include within it, its institutional context.

We can observe how practice is here conceived as a location, in which practice elements are contained and are relationally linked the one to the other. Nevertheless, once we recognize that knowledge is an activity and an activity situated in working practices, we can move on and wonder whether materiality has agency and which effect is produced in knowing practices once agency is attributed to both human and nonhumans working together.

\section{Humans and nonhumans working together: a posthumanist practice theory}

For the moment, I keep the term nonhuman to acknowledge that for a long time within a practice theory-inspired by an actor-network sensibility-the nonhuman was used 
as the 'other' of human beings including objects, tools, technologies and any other materiality hanging in a practice.

A concern with materials of different kinds, with language, discourses, with humans, and with their precarious relations was the foundation for conceiving a practice as a knowledgeable mode of ordering heterogeneous materials into a provisional and productive assembly.

Within a project of establishing a material-semiotic relationality in which all the practice elements define and shape each other, humans are not privileged over materials as the main (and the only) source of action. The demarcations between 'social' and 'natural', 'nature' and 'culture', 'structure' and 'agency', 'humans' and 'nonhumans' are the effect of epistemic practices, and 'material agency' is temporally emergent in relation to practice (Pickering 1995). Human and nonhuman, meaning and materiality, big and small, macro and micro, social and technical, these are just some of the dualisms undone by the relational epistemology of practice. Therefore, an epistemology of practice is not limited to operating a connection across dualisms, rather it is a proposal to see how all the demarcations are effects of epistemic practices.

People are relational effects in the same way that objects are and within a situated practice, humans, discourses, and materials achieve agency in their being entangled. In this sense, we can use the concept of sociomaterial practices (Orlikowski, 2007). The purpose of these concepts is to emphasize that 'materiality is integral to organizing, positing that the social and the material are constitutively entangled (italics in the original) in everyday life' (Orlikowski, 2007, pp. 1437). The term refers to the fact that within a practice meaning and matter, the social and the technological are inseparable and one cannot be defined without reference to the other. A position of constitutive entanglement privileges neither humans nor technologies, neither knowing nor doing; it does not even link them in a form of mutual interdependence (as in two-way interactions).

It was from Wanda Orlikowski's and Susan Scott's (2008) work that terms such as entanglement, sociomateriality, intra-action, taken from Karen Barad's (2003; 2007) work, were translated into organization studies. The humanist practice theory was criticized and posthumanism based on the relationalism between the social and the technical joined other families of posthumanist epistemology (Braidotti, 2013). Some examples of posthumanist epistemology are the feminist new materialism (Alaimo \& Hekman, 2008), the affect 
theories (Clough, 2007), the animal studies (Wolfe, 2010) among others (Taylor, 2016). The aim of a posthuman sociology is to identify and map distributed agency.

A posthumanist conception of practice enables a different conception of the 'social' in theories of social practice since the social is not the 'other' of the 'natural'. The social is generated by material practices, and an empirical study of social practices focuses on how the social is done and holds together. The concept of sociomaterial practices implies not only that the social and the material are co-constituted, but also that nature and culture are entangled. It has a methodological corollary that entails studying how, within a practice, bodies (humans and more-than-humans), matter, and discourses are expressions of the same sociomaterial world. The term 'embodiment' expresses how the nature/culture division is blurred in the materiality of bodies encountering a material-semiotic environment. When we study working practices empirically, we should focus on how practical knowledge is embodied and how practitioners rely on sensible knowledge (Strati, 2007) in order to take a practice forward (Gherardi, 2012; 2017). The centrality of bodies and sensible knowing - in approaching practices is self-evident, not only because humans 'are' bodies (Merleau-Ponty, 1945) but also because bodies stand in between the dualism of persons and things (Esposito, 2014). Nevertheless, the body has been overlooked even when humans are considered the carriers of practices. Therefore, to the definition of practice as an array of 'doings' and 'sayings' (Schatzki, 2001), I prefer to enlarge the focus to (knowledgeable) 'seeing, saying, and doing' (Gherardi, 2006), where seeing is taken as the bodily activity representative of all sensible knowing. Our Western culture is mainly visual and for this reason with 'seeing' I locate within practice all the other bodily knowing, like hearing, tasting, touching in order to stress how activities and discourses are grounded in an embodied and pre-verbal presence and that in becoming a practitioner one learns knowledgeable bodily competences that are practice-specific.

\section{Embodied, embedded, and other elusive knowledges}

Embodiment is a concept present in practice theories, and Reich and Hager (2014) consider it one of the six threads of the literature on practice (the others are: knowing-inpractice; sociomateriality of practices; relationality; historical and social shaping of practices; emergent nature of practices). In fact, it is now widely accepted within the social sciences that selfhood is not only social, but also materially embodied. 
The idea that knowledge is embedded in situated practices is widespread, and I like to recall how the turn to practice within the literature on learning and knowing rediscovered the concept of practice as a way out from the two dominant conceptions of learning, either cognitivist or reified. Practice theories entered the debate on organizational learning and knowing inserting a distance from an individualistic conception of knowledge as residing in the mind and supporting the claims of a social learning theory viewing learning as legitimate participation in the practices of a community (see Gherardi, 2009).

At the same time, the turn to practice inserted a distance from the commodification of knowledge, that in the years 2000 dominated the literature on knowledge management, conceiving knowledge a commodity as any other (Gherardi, 2000). The focus on practice theory, within this debate, was devoted to how knowledge was kept inside the practices of a community, how it was transferred to the new members, and how it was changed by being in use. This debate is initially in debt with the formulation of learning as peripheral legitimate participation within a community of practice, but later the concept was turned upside down and the focus was devoted to the practices that generate a community in their accomplishment (Gherardi, 2009).

The concern was on practices as sites of knowing (Nicolini, 2011); on knowledge that was tacit, sticky, non-translated into words, corporeal, haptic and generally aesthetic (Strati, 1999, 2007). Within a sociology of learning:

“Knowledge is not what resides in a person's head or in a book or in data banks. To know is to be capable of participating with the requisite competence in the complex web of relationships among people and activities. On this definition it follows that learning is always a practical accomplishment. Its goal is to discover what to do; when and how to do it, using specific routines and artefacts; and how to give, finally, a reasonable account of why it was done. Learning, in short, takes place among and through other people" (Gherardi et al., 1998: 274).

Embodiment and embodied knowledge have been among the main reasons for the turn to practice around the year 2000, leaving behind the classic practice theories of the first generation such as Deweyan pragmatism or activity theory (Miettinen et al. 2009). Thus, organizational and working practices have been considered as the locus of knowledge 
production, circulation and transformation Tacit knowing, sensible knowledge, and the knowing body become the main elements for approaching practices as the containers of knowing subjects and known objects. From this perspective embodied knowledge and embodied knowing have been studied as competence, mainly as individual competence but also as a learned collective one. Embodied knowledge, as a type of knowledge where the body knows how to act, leads to a skillful performance that emerges from and through reciprocal relations encompassing the body-in-the-world and the world-in-the-body (Dall'Alba et al., 2018). The body, the gendered body, and embodied knowing are highly relevant for practicebased studies (Yakhlef, 2010). And organizational aesthetics has greatly contributed to directing attention to knowing through the hands, the ears, the nose and all the human senses involved in working practices.

The knowledge that is kept, distributed, fragmented, used and transmitted while practicing is embodied, sensory and atmospheric. For an empirical study of practices, the problem becomes how to articulate in words embodied experiences (tacit, aesthetic, embodied), i.e. those 'elusive knowledges' (Toraldo, et al. 2016) that are learnt but kept silent within a working practice. The term 'elusive knowledges' refers to 'those forms of knowledge that escape literal representation through discourse including alphanumeric symbols' (Toraldo, et al. 2016: 3). Nevertheless, they may be made articulable by the use of videobased methods. In fact, the authors value video's ability, in conjunction with interviews or ethnography, to explore the interactions of humans with material settings that reveal facets of nonverbal communication. The authors suggest that video-based methods facilitate access to embodied practical knowledge not because they capture the objective reality of practical knowing but because they promote cross-modal translations (visual/textual) productive of new knowledge that can prompt reflexivity on knowing-in-practice.

\section{Knowing-in-practice: realities are enacted in practices}

Focusing on practices rather than on persons or structures has an implicit methodological corollary: a practice can be seen as the locus of knowledgeable doing, learning and organizing (as we have proposed in the previous sections), at the same time a practice can be seen as way of knowledgeable doing (as in what follows). The second definition implies to consider a practice as a mode of ordering sociomaterial relations and 
thus inquiry into how practices generate (an unstable) order, and how ordering becomes a relational and performative effect of practices.

To give a simple example of how different 'objects' are the product of different practices (this is a way of expressing the abstract term of empirical ontologies), I shall narrate an exemplar story that has been told several times in the literature on Science and Technology Studies (Joks \& Law, 2017; Law \& Joks, 2017; Law \& Lien, 2013; Law \& Singleton, 2013). In my narrative I relay mainly on Law and Lien (2013: 365-369), and my plotline is developed around the question: What a farmed Atlantic salmon is if it is treated as an effect of relational practices?

The story comes from an extended ethnography of farming practices, whose focus is on salmon-human enactments in which salmon become slippery and elusive, and farming practices enact separations between humans and salmon. The texture of farming practices enacts what a salmon is, since they define the qualities of both salmon and humans.

Imagine that we observe a practitioner fishing dead salmon out of the water, a fish that is dead or alive, or injured. If it is dead it is also something to be put in a bucket and dumped in a tank filled with formic acid and other dead fish. In this case a salmon (precisely a dead salmon) is an object that needs to be sifted out and removed.

Imagine now that we open a scientific book searching for a definition of salmon, and there we find a reference to Linnaean systematics, and the physical characteristics of the salmon. Another salmon is enacted through scientific categories and another set of relations are described where the salmon is located into a web of links that include a taxonomic system, particular genetic attributes, and a specific lifecycle, geographical range and feeding characteristics. An Atlantic salmon is here a scientific object that is done in the context of specific scientific practices, and it is different from the salmon being done by the practitioner at the farm.

If we imagine moving in the farm, we observe the practice of vaccinating young salmon or parr that are pumped up through a pipe, arrive in batches in a gush of water, and drop into a container filled with water and anaesthetics. Once they go limp, they are lifted in a metal basket and decanted onto a stainless-steel work surface behind a rapidly moving conveyer belt. What is the salmon here? Another set of relations are established between: i) the practitioner's hands that reach out, lift the fish, and drop them onto the conveyer belt, ii) the embodied knowledge in the hands that have learnt how to do the sorting, iii) the red or green light of the machine processing the fish (in the right or wrong way), and iv) the wet, 
busy and noisy vaccination cabin surrounded by pipes and cables, and filled with buckets, tables and machines. Here we see how the 'the salmon passive', or perhaps 'the salmon not passive enough' is enacted in a web of distributed agency, where salmon passivity and human or vaccination-machine agency are being done relationally, and moment-bymoment, through continual effort, work, and redoing, and this knowledgeable doing is more or less precarious. The object of this practice is fluid - a salmon may change in form between practices - and it is done within a choreography that should be sustained since there is no 'salmon' outside the practices that enact it.

What we have observed within a practice (either cleaning the water tank or vaccinating the parr) can be observed in the texture of ordering practices forming the farming. Other practices measure the 'right' salmon, separating it from the rejected ones, the losers who grow too slowly and follow a different trajectory that I do not exemplify here. The point is that in a relational world, control and ordering are impossible without lack of control and disordering. In conclusion, the story of the 'salmon multiple' of aquaculture is a story of fluidity and multiplicity where the 'what is a salmon' is performed through overlapping practices from the moment of fertilization to its final trip to the slaughterhouse.

A practice approach operates a shift from what a thing is (and why) to how a thing is done within situated sociomaterial practices. Generally, describing a practice as 'situated' means considering the organization of the activities as emerging in situ from the dynamics of knowledgeable practicing. With reference to Suchman's (2007) distinction between plans (ex-ante rationality) and situated action (contingency), we can say that a practice emerges (in time and space) as the effect of situated practicing. I illustrated it with the story of 'what a salmon is', and I wish to add and stress that also the researchers' epistemic practices contribute to the empirical ontology of the multiple salmon and considering the researchers inside the practice they study means that the researchers make the salmon while the salmon makes the researchers.

Not only can the salmon be described as a fluid entity that shifts its shape as it moves between practices (Laet \& Mol, 2000), other well-known examples of empirical ontologies may be found in Mol's (2002) work in relation to the multiple body in medicine with lower limb atherosclerosis, or Alzheimer's disease (Moser, 2008), or anaemia (Mol \& Law, 1994). For example, Annemarie Mol (2002) describes ethnographically a patient's body and its disease moving from one hospital ward to another to see how they become different objects. 
She argues, in material-semiotic mode, that each practice generates its own material reality and not that there are different perspectives on a single disease.

Mol coined the label praxiography, which unfortunately did not have a wide following, for denoting it as 'a story about practices'. Praxiography is a method to 'stubbornly take notice of the techniques that make things visible, audible, tangible, knowable' (Mol, 2002: 23). A similar concern is expressed by the term 'ethnography of the object' (Bruni, 2005) that, in following the trajectory of a clinical health record in a hospital, incorporates Latour' (1987) methodological injunction to 'follow the actor' and translate it in respect to the agency of the material actants.

\section{A story about practices, a texture of practices, and their agencement}

For an empirical study of a practice and its connection with other interdependent practices within a texture, the definition of practice as an agencement has proved simple and useful (Gherardi, 2016). Agencement is a word which has the idea of agency in its root, and is currently used in French, as a synonym for 'arrangement', 'fitting' or 'fixing'. It has been used as a philosophical term by Deleuze and Guattari (1987) with the sense of 'in connection with' and has been recently re-introduced into the social science vocabulary by Callon and colleagues (2013) to talk of economic performativity. It expresses clearly the word-play of the term agencement since it is 'an actor' in the sense of a sociotechnical assemblage and at the same time it has agence, agency. Similarly, when we look at a practice, we can see how the sociomaterial relations that tie bodies, artifacts, discourses, technologies, and rules together are performed within it and with other practices, and how agency is its effect.

Within a practice, in its unfolding, neither humans, nor nonhumans, nor discourses have priority. If we describe the process of agencement as a process of heterogeneous engineering, we can say that all the resources necessary for practicing are the stuff of what is connected. It is difficult to enumerate the ingredients of a practice, since a resource for action becomes a resource only within an assemblage of relationships. In the language of actor-network theory, we should say that elements are performed in, by and through the relations in which they are located, and if the relations do not hold fast by themselves, they need to be performed. 
The concept of agencement can prove useful for a practice-based study, since in studying a practice the researcher may empirically follow and describe the process whereby humans, artifacts, rules, technologies, sensible knowledge, legitimacy and any other practice resource become connected thanks to a collective knowledgeable doing. It is not a final product (as the English translation in 'assemblage' suggests), but it calls for a process approach looking for temporality and becoming, agencement calls for 'agencing', as Cochoy (2014) prefers to name it.

What we call 'practice' is a heuristic move that de-territorializes and re-territorializes the unfolding of a flow of practicing. When we put boundaries around 'a' practice, trying to see when (and where) it begins and where (when) it ends, we are doing a heuristic operation (an agential cut in Barad's terms), since it is within practicing that connections are established and dissolved without a pre-defined order; and it is the process of agencement (of connecting with) that creates it. These connections are those of the rhizome, which has no beginning or end but is always in between, in motion.

Therefore, the passage from the noun 'practice' to the verb 'practicing' implies not only a move towards a process view, but especially a passage to temporality and to the situated activity of agencement as the activity of establishing connections. But what is connected within a practice and how are practices connected?

A story about the empirical study of safety in construction industry may illustrate how 'safety' is the sociomaterial object emergent from the agencement of a texture of practices (Gherardi \& Nicolini, 2000; Gherardi, 2006). Like the salmon in the previous story about multiplicity, also safety knowledge and organizational safety learning are enacted in situated practices across a multiplicity of sites, and what we value as 'safety' within a society may be conceived as a collective competence developed alongside emergent practices within and across the boundaries of one organization, one industry, one organizational and institutional field. For describing empirically the agency that connects all the practices of 'doing safety' we can trace the sociomaterial enactments of knowing and learning at various point in time. For example, we can track a novice who enters a community of practices (Gherardi, Nicolini \& Odella, 1998a) and how s/he learns what is safe working and organizing and what is risky. At the same time, we trace how the community teaches through words, discourses, and silences, and we follow how this knowledge is embodied, embedded in sociomaterial relations and is contingent and provisional, so that a practice is always practiced for another first time (Garfinkel, 1967). In a construction site, a specific working activity is performed 
more or less safely within the agencement that keeps a practice together. Learning safety means knowing how to behave as a competent member in a culture of safety practices. It means that within a practice learning is not distinct from knowing in practice. Working practices are specific to different occupations and professions, that are interdependent within the single construction site and that enter into conflicts and negotiations over the meaning and the multiple enactments of how to accomplish safe working and organizing practices. Moving along the connections among the working practices of one community and another interdepent one, we can explore how the culture of certain occupational practices are enacted when different communities of practice explain why accidents happen (Gherardi, Nicolini \& Odella, 1998b). Similarly, when a firm recovers after a major accident (Gherardi, 2004), we can track how (and if) previous practices are challenged, changed, or reinforced, and who and what enter into a new agencement. Moving along the rhizomatic lines of connection within the texture of safety practices we can inquire on how an institutional field deals with safety regulations (Gherardi \& Nicolini, 2002), and how the regulative practices (at national and international level) go back to the single construction site and to the individual novice learning the use of a risky tool. The end of this story about safety practices is that what counts as 'safety' within an historical context is the provisional and contested enactment of a texture of practices that acquires agency in their being connected and disconnected. In other words, when the researchers aim to inquire on the actual processes of organizing, they may trace how a flow of situated activities are connected into streams of action and the researchers may move along the threads of a texture of practices, from activities within a practice to practices connected to other practices. In fact, practices have no boundaries except those that the heuristic operation of a researcher establishes. Practice does not 'exist' in nature, researchers do not 'find' it, rather practice is always conceptually constructed.

Another story about agencement may be told taking the opportunity of a huge debate that the rumor about the introduction of a wireless bracelet (a newly-announced practice) at Amazon in Italy, where two new centers have been opened, for a total of 1,6oo jobs. The bracelet, just patented in the US, has been designed to speed up the search for products stored in warehouses by employees, monitoring where they put their hands, vibrating to guide them in the right direction and actually controlling all their movements. These details are to be transmitted on the minicomputer to the employee's wrist to take the goods, put it in a box and switch to the next task. The news of the patent was taken from all newspapers, 
and almost all the exponents of the government and the political parties reacted on social media, accusing the company of reducing their employees as new slaves of the capitalist system. The Speaker of the House Laura Boldrini, declared that "Working is not a crime," and called the proposal "degrading and offensive". Even the Prime Minister Paolo Gentiloni had a word in, saying that the challenge facing Italians was "quality jobs, not jobs with wristbands", and that Italy (differently for other countries) has labour laws that apply to every company.

What did a wireless bracelet - a new tool that was not yet put into use - produce? It made evident the sociomaterial relations in a texture of practices, producing an agencement in which the reputation of a company (that turns employees, paid little, into human robots who work near real robots, carrying out repetitive packaging tasks as quickly as possible, with the goal of achieving the ambitious delivery targets set by Amazon) was materialized. Moreover, the wireless bracelet produced the visibility of retail services, that work with thin margins of profit, that minimize the cost of labor, that use work contracts that advise workers of their schedule time with little notice, that use algorithms to organize staffing according to the optimization of presence. We can see the bracelet's performativity not only in its capacity to make visible the connections between working and organizing practices, but also in its capacity to bring to light a question of moral (and not only economic) value. The bracelet made audible/readable/tangible/knowable a societal issue: what is the value of work? What is the meaning of work in a life and in a society? The political and ethical materialization of a practice within a society (and differently from other societies) is made sayable.

Within the study of work and organization one reason for a practice approach that leaves behind the assumption that actions spring from the intentionality and values of human beings, is that the focus on 'a' practice situated in any point within a texture of practices, enables the researchers to move along many lines of connections in any direction, following the connections in action. A texture of practices may be empirically explored and described either following the connections that from one practice move along radial lines, like in the web of a spider (as I prefer to say) or along the two moves of a zooming-in and zooming out that Nicolini (2010) suggests.

\section{Conclusion}


The empirical study of practices may be approached from different angles and with different knowledge interests, and consequently practice as a knowledge object is multiple and fluid. Knowledge objects are characterized by their question-generating character, and they can never be fully attained since - as Knorr Cetina (2001: 190) writes - 'epistemic objects are always in the process of being materially defined, they continually acquire new properties and change the ones they have'. In this essay, I have assumed the relation between practice and knowledge as my compass for arguing that knowing is a generative social practice.

Within the literature on organizational learning and knowing, the knowledge object 'practice' has been modelled following the desire to avoid the cognitive formulation of knowledge as residing in people heads and, at the same time, to avoid the image of a commodified knowledge valued in economic terms. Therefore, practice can be considered as a figure of the discourse on knowing, learning and organizing, where learning is understood as competent sociomaterial participation in situated practices, knowing is embodied and entangled with doing, and practice takes the form of a mode of ordering heterogeneous materials, that achieve agency through their performative connections. Therefore, in saying that practices are situated modes of ordering and 'agencing' it is said that they are always emerging from practicing and, in their recursiveness, they become stabilized, institutionalized, and become objects of attachments.

The question-generating power of formulating practice as the locus of learning and knowing is related to the inquiring into how knowing-in-practice is accomplished and how the heterogeneous elements are stitched together. One impetus for looking into the practice realm comes from conceiving practice as the container of elusive knowledges, embodied ways of knowing, pre-verbal and pre-individual forces that operate beyond the speaking subject and its presumed centrality.

These kinds of questions are grounded in an Actor-network sensibility that harbors an onto-epistemology informed by relationality and performativity. Thus, the object of knowledge 'practice' is displaced from a humanistic sociology in which actors are the main source of action (in the view of 'actors and their practices') to a post-humanistic formulation of practice theory as sociomateriality in which humans, materials, more-than-humans, discourses and knowledges are entangled within a practice, and practices are woven in a texture of practices. What keeps a practice or a texture of practices (temporally) connected 
or disconnected within an agencement? The glue may come from the power of association, communication and affect, when matter matters (in Barad's words).

The knowledge object 'practice' is constructed differently within different disciplinary traditions and different knowledge interests and there is no point in engaging in a war of epistemologies when we can learn to switch lenses and appreciate the dynamics of difference and differing. Practice is multifaceted: a theoretical starting point and an empirical focus for organizational inquiry. Practice as epistemology contributes to the empirical study of how we come to know what we know and how in knowing the object is always indeterminate and changing.

\section{Acknowledgements:}

I am entirely responsible for this reflection on the place of knowledge in practice theory. However, it would not have been possible without the kind invitation of Marcelo Bispo to reflect on my own contribution to practice-based studies and to disentangle what he calls my 'hybrid' approach. We discussed it at length, in Trento when he was visiting RUCOLA, in several international conferences when we met, by mail and by skype conversations, and still I do not see it. Nevertheless, I like the idea of hybridizing and creating new hybrid thoughts for the future. I thank Marcelo for his generosity as a scholar and a friend. Another special thank goes to Marie Manidis for the pleasure of our conversations and her continuous support.

A first version of this article was discussed with the colleagues of 'Media of Cooperation' at the University of Siegen, and I wish to thank Jörg Potthast, Sebastian Giessmann, Tobias Röhl, Julian Genner and all the other participants for the enjoyable conversation. 


\section{References}

Alaimo, S., \& Hekman, S.. (Eds.). (2008). Material feminisms. Bloomington: Indiana University Press.

Baert, P. (2005). Philosophy of the social sciences: towards pragmatism. Cambridge: Polity.

Baert, P. \& Domínguez Rubio, F. (2009). Philosophy of the social sciences. In B. Turner (Ed.). The new Blackwell companion to social theory (pp. 60-80). Oxford: Blackwell Publishing.

Barad, K. (2003). Posthumanist performativity: toward an understanding of how matter comes to matter. Signs, 28(3), 801-831.

Barad, K. (2007). Meeeting the university halfway: quantum physics and the entanglement of matter and meaning. Durham: Duke University Press.

Bell, S. E. (2009). DES daughters, embodied knowledge, and the transformation of women's health politics in the late twentieth century. Philadelphia: Temple University Press.

Berger, P., \& Luckmann, T. (1966). The social construction of reality. Garden City, NY: Doubleday.

Braidotti, R. (2013). The posthuman. Cambridge, UK: Polity Press.

Bruni, A. (2005). Shadowing software and clinical records: on the ethnography of nonhumans. Organization, 12(3), 357-378.

Callon, M. (1986). The sociology of an actor-network: the case of the electric vehicle. In M. Callon, J. Law \& A. Rip (Eds.), Mapping the dynamics of science and technology: sociology of science in the real world. Basingstoke: Macmillan.

Callon, M. et al., (2013). Sociologie des agencements marchands, Paris : Presses des Mines.

Clarke A., \& Fujimura J. (1992). The right tools for the job: at work in twentieth century life sciences. Princeton: Princeton University Press. 
Clough, P. T. (with Jean Halley). (2007). The affective turn: theorizing the social. Durham, NC: Duke University Press.

Cochoy, F. (2014). A theory of 'agencing': On Michel Callon's contribution to organizational knowledge and practice. In P. Adler, P. du Gay, G. Morgan, \& M. Reed (Eds.), The Oxford handbook of sociology, social theory, and organization studies: Contemporary currents (pp. 106-124). Oxford: Oxford University Press.

Collins, HM. (1985). Changing order: replication and induction in scientific practice. Beverly Hills: Sage Publications.

Dall'Alba, G., Sandberg, J., \& Sidhu, RK. (2018). Embodying skillful performance: coconstituting body and world in biotechnology. Educational Philosophy and Theory, 50(3), 270-286.

Deleuze, G., \& Guattari, F. (1987). A thousand plateaus. (Trans. Brian Massumi). Minneapolis: The University of Minnesota Press.

Epstein, S. (1996). Impure science: aids, activism, and the politics of knowledge. Berkeley: University of California Press.

Esposito, R. (2014). Le persone e le cose. Torino: Einaudi.

Gadamer, HG. (1975). Truth and method. London: Sheed \& Ward.

Garfinkel, H. (1967). Studies in ethnomethodology. Cambridge: Polity.

Gherardi, S. (2000). Practice-based theorizing on learning and knowing in organizations: An introduction. Organization, 7(2), 211-23.

Gherardi, S. (2001). From organizational learning to practice-based knowing. Human Relations, 54(1), 131-9.

Gherardi S. (2004). Translating knowledge while mending organizational safety culture. Risk Management: An International Journal, 6(2), 61-80.

Gherardi, S. (2006). Organizational knowledge: the texture of workplace learning. Oxford: Blackwell. 
Gherardi, S. (2009). Community of practice or practices of a community? In S. Armstrong, \& C. Fukami (Eds.). The Sage Handbook of Management Learning, Education, and Development. (pp. 514-530), London: Sage.

Gherardi, S. (2012). How to conduct a practice-based study: problems and methods, Cheltenham, Gloss: Edward Elgar.

Gherardi, S. (2016). To start practice-theorizing anew: the contribution of the concepts of agencement and formativeness. Organization, 23 (5), 680-698.

Gherardi S, (2017). Sociomateriality in posthuman practice theory. In S. Hui, E. Shove, \& T. Schatzki (Eds.) The nexus of practices: connections, constellations, and practitioners. (pp. 38-51), London: Routledge.

Gherardi, S., \& Nicolini, D. (2000). The organizational learning of safety in communities of practice, Journal of Management Inquiry, 9(1), 7-18.

Gherardi S, \& Nicolini, D. (2002). Learning in a constellation of interconnected practices: canon or dissonance? Journal of Management Studies, 39(4), 419-36.

Gherardi S., Nicolini D., \& Odella F., (1998a). Toward a social understanding of how people learn in organizations: the notion of situated curriculum. Management Learning, 29(3), 273- 298.

Gherardi S., Nicolini D., \& Odella F., (1998b). What do you mean by safety? conflicting perspectives on accident causation and safety management inside a construction firm. Journal of Contingencies and Crisis Management, 7(4), 202-213.

Giddens, A. (1984). The constitution of society: outline of the theory of structuration. Cambridge: Polity.

Giddens, A. (1993). New rules of sociological method. Cambridge: Polity.

Gieryn, T. F. (1999). Cultural boundaries of science: credibility on the line. Chicago: University of Chicago Press.

Joks, S. \& Law, J., (2017). Sámi salmon, state salmon: TEK, technoscience and care. The Sociological Review Monographs, 65(2), 150- 171. 
Knorr Cetina, K. (1981). The manufacture of knowledge: an essay on the constructivist and contextual nature of science. Oxford: Pergamon Press.

Knorr Cetina, K. (1999). Epistemic cultures: how the sciences make knowledge. Cambridge, MA: Harvard University Press.

Knorr Cetina, K. (2001). Objectual practice. In T.R. Schatzki, K. Knorr Cetina \& E. von Savigny (Eds.). The Practice Turn in Contemporary Theory (pp. 175-88). London: Routledge.

Laet, M. de \& Mol, A. (2000). The Zimbabwe bush pump: Mechanics of a fluid technology. Social Studies of Science, 30(2), 225-263.

Latour, B. (1987). Science in action: How to follow scientists and engineers through society. Harvard: Harvard University Press.

Latour, B., \& Woolgar, S. (1986). Laboratory life: the construction of scientific facts. Princeton: Princeton University Press.

Law, J. (2009). Actor network theory and material semiotics. In B. Turner (Ed.). The New Blackwell companion to social theory (pp.141-158), Oxford: Blackwell Publishing.

Law, J., \& Joks, S. (2017). Luossa and Laks: salmon, science and LEK. Revue d'Anthropologie des Connaissances, 12(2).

Law, J., \& Lien, M. E. (2013). Slippery: Field notes in empirical ontology. Social Studies of Science, 43(3), 363-378.

Law, J., \& Singleton, V. (2013). ANT and politics: working in and on the world. Qualitative Sociology, 36(4), 485-502.

Lynch, M. (1993). Scientific practice and ordinary action. New York: Cambridge University Press.

Merleau-Ponty, M. (1945/2012). Phenomenology of perception. London: Routledge.

Miettinen, R., Samra-Fredericks, D. \& Yanow, D. (2009). Re-turn to practice: an introductory essay. Organization Studies, 30(12), 1309-1327. 
Mol, A. (2002). The body multiple: ontology in medical practice. Durham, NC: Duke University Press.

Mol, A. \& Law, J. (1994). Regions, networks and fluids: anaemia and social topology. Social Studies of Science, 24 (4), 641-71.

Moser, I (2008). Making Alzheimer's disease matter: Enacting, interfering and doing politics of nature. Geoforum, 39, 98-110.

Nicolini, D. (2010). Zooming in and out. studying practice by switching lenses and trailing connections. Organization Studies, 30(12), 1391-1418.

Nicolini, D. (2011). Practice as the site of knowing: Insights from the field of telemedicine. Organization Science, 22(3), 602-620.

Nicolini, D. (2012). Practice theory, work, and organization: an introduction. Oxford: Oxford University Press.

Orlikowski, W. (2002). Knowing in practice: enacting a collective capability in distributed organizing. Organization Science, 13, 249-273.

Orlikowski, W. (2007). Sociomaterial practices: Exploring technology at work. Organization Studies, 28(9), 1435-1448.

Orlikowski, W. \& Scott, S. (2008). Sociomateriality: Challenging the separation of technology, work and organization. The Academy of Management Annals, 2(1), 433-474.

Pickering, A. (1995). The mangle of practice: time, agency, and science. Chicago: University of Chicago Press.

Reich, A., \& Hager, P. (2014). Problematising practice, learning and change: Practice-theory perspectives on professional learning. Journal of Workplace Learning, 26(6/7), 418-431.

Rheinberger, H. (1997). Toward a history of epistemic things: synthesizing proteins in the test tube. Stanford: Stanford University Press. 
Roosth, S. \& Silbey, S. (2009). Science and technology studies: from controversies to posthumanist social theory. In B. Turner (Ed.). The New Blackwell Companion to Social Theory, pp. 451-474, Oxford: Blackwell Publishing.

Rorty, R. (1980). Philosophy and the mirror of nature. Oxford: Blackwell.

Rorty, R. (1982). Consequences of pragmatism. New York: University of Minnesota Press.

Traweek, S. (1988). Beamtimes and lifetimes: the world of high energy physicists. Cambridge, MA: Harvard University Press.

Schatzki, T. (2017). Practices and people. Teoria e Prática em Administração, 7(1), 26-53.

Schutz, A. (1962). Collected papers I: the problem of social reality. The Hague: Martinus Nijhoff.

Schutz, A. (1964). Collected papers II: studies in social theory. The Hague: Martinus Nijhoff.

Schutz, A., \& Luckmann, T. (1973) The Structures of the Life-World. London: Heinemann.

Sciortino, G. (2009). Functionalism and social systems theory. In B. Turner (Ed.), The new Blackwell companion to social theory (pp. 106-123), Oxford: Blackwell Publishing.

Shove, E., Pantzar, M. \& Wilson, M. (2012). The dynamics of social practice: everyday life and how it changes. London: Sage.

Star S.L., \& Griesemer J. (1989). Institutionnal ecology, 'translations', and boundary objects: amateurs and professionals on Berkeley's museum of vertrebate zoologie. Social Studies of Science, 19(3), 387-420.

Strati, A. (1999). Organization and aesthetics. London: Sage.

Strati, A. (2007). Sensible knowledge and practice-based learning. Management Learning, 38(1), 61-77.

Suchman, L. (2007). Human-machine reconfigurations: plans and situated actions. (2. ed.), Cambridge: Cambridge University Press. 
Taylor, C. A. (2016). Posthuman research practices in education. London: Palgrave Macmillan.

Toraldo, M. L., Islam, G., \& Mangia, G. (2016). Modes of knowing: Video research and the problem of elusive knowledges. Organizational Research Methods, 1094428116657394.

Turner, B., (2009). The New Blackwell Companion to Social Theory, (pp. 451-474). Oxford: Blackwell Publishing.

Weinberg, D. (2008). The Philosophical Foundations of Constructionist Research. In J. K. Holstein \& J. Gubrium (Eds.), The handbook of constructionist research. New York: Guilford Press.

Wittgenstein, L. (1968). Philosophical investigations. Oxford: Blackwell.

Wolfe, C. (2010). What is posthumanism? Minneapolis: University of Minnesota Press.

Yakhlef, A. (2010). The corporeality of practice-based learning. Organization Studies, 31(4), 409-430. 
${ }^{\mathrm{i}}$ In this section I refer the reader mainly to Turner (2009), The New Blackwell Companion to Social Theory, since the debate on the changed nature of knowledge in contemporary philosophies is quite extensive and cannot be presented extensively here. 